\title{
Effects of ethanol and pentobarbital in mice of different ages
}

\author{
ERNEST L. ABEL \\ Research Institute on Alcoholism, 1021 Main Street, Buffalo, New York 14203
}

Older animals "slept" twice as long as younger animals following injection of ethanol $(4 \mathrm{~g} / \mathrm{kg})$, although blood alcohol concentrations at time of awakening were not significantly different. Older mice also slept approximately twice as long as younger mice following injection of pentobarbital $\mathrm{Na}(50 \mathrm{mg} / \mathrm{kg})$. Ethanol $(3 \mathrm{~g} / \mathrm{kg})$ depressed gross motor activity of older animals more than younger animals. When tested for their preference for various concentrations of ethanol vs. water, younger animals exhibited a greater preference than older animals at all but two of the concentrations tested.

Epidemiological studies (e.g., Barnes \& Russell, 1977; Cahalan \& Cisin, 1968) indicate that the overall incidence of alcohol intake among the elderly is less than that for the population as a whole. However, in treatment facilities where alcohol has been diagnosed as an underlying problem, the proportion of elderly patients examined for psychiatric problems who are subsequently found to be suffering from alcohol-related disorders is rather formidable, the proportion ranging from $15 \%$ to $50 \%$ (Epstein \& Simon, 1970; Schuckit \& Miller, 1976; Zimberg, 1974). These findings suggest that although the overall incidence of alcoholism may be lower in the elderly, the elderly may be more susceptible to the effects of alcohol. In this regard, age-related differences in the action of alcohol on membrane-bound synaptosomal $\left(\mathrm{Na}^{+}-\mathrm{K}^{+}\right)$ATPase have been noted in animals and man (Sun \& Samorajski, 1975). In animals, age-related differences in ethanol metabolism and toxicity have also been noted (Wiberg, Samson, Maxwell, Caldwell, \& Trenholm, 1971; Wiberg, Trenholm, \& Caldwell, 1970).

The present studies are aimed at extending these findings by examining the effects of ethanol on "sleep time," general motor activity, and preference for ethanol, in mice of two different ages. In addition, "sleep time" in response to pentobarbital was also investigated to determine if the differential effects of responsiveness to alcohol associated with age are peculiar to ethanol or are also true of other drugs, such as pentobarbital.

\section{METHODS AND PROCEDURES}

\section{Subjects}

The subjects were female $\mathrm{C}_{57} \mathrm{BL} / 6 \mathrm{~J}$ mice. Animals in Group 1 were 2-3 months of age; animals in Group 2 were $12-13$ months

The technical assistance of Barbara Dintcheff is gratefully acknowledged. Dr. Hebe B. Greizerstein kindly carried out drug analyses by gas chromotography. of age. Animals were obtained from Jackson Laboratories (Bar Harbor, Maine). The animals were individually housed and placed on ad-lib food and water. Separate groups of animals were used for each test procedure.

\section{Ethanol-Induced Sleep}

Eight animals per group were injected (IP) with ethanol $(4 \mathrm{~g} / \mathrm{kg}, 20 \% \mathrm{w} / \mathrm{v})$. The time from loss until recovery of the righting response (animal righted itself twice within $15 \mathrm{sec}$ ) was designated as "sleep time."

At the time of recovery, the animals were sacrificed and blood samples $(25 \mu \mathrm{l})$ were taken from the heart. The samples were deproteinized with $\mathrm{ZnSO}_{4}$ and $\mathrm{Ba}(\mathrm{OH})_{2}$. Propanol was added as an internal standard. Blood alcohol concentration (BAC) was analyzed by gas chromatography by the method of Greizerstein and Smith (1973).

\section{Pentobarbital-Induced Sleep}

Ten animals per group were injected (IP) with sodium pentobarbital $(50 \mathrm{mg} / \mathrm{kg})$. "Sleep time" was determined as described for ethanol.

\section{General Motor Activity}

Animals (10-12 per group) were injected (IP) with ethanol $(0-3.0 \mathrm{~g} / \mathrm{kg}, 20 \% \mathrm{w} / \mathrm{v})$. Fifteen minutes after injection, the animals were individually placed into single direct-beam photocell activity cages for $20 \mathrm{~min}$. The cages were identical in size to those used to house the animals $(28 \times 16.5 \times 12.5 \mathrm{~cm})$.

\section{Preference for Ethanol}

The animals ( $N=10$ per group) were individually housed in Plexiglas cages. An ascending series of ethanol concentrations of $5 \%, 10 \%, 15 \%, 20 \%, 25 \%, 30 \%$, and $35 \% \mathrm{v} / \mathrm{v}$ were presented along with tap water during consecutive 8-day tests. The position of the two bottles was alternated every 4th day. All subjects were tested with all solutions. Preference scores were expressed as the ratio of $\mathrm{EtOH} / \mathrm{EtOH}+\mathrm{H}_{2} \mathrm{O}$.

\section{RESULTS}

The data for ethanol-induced "sleep time"' are presented in Figure 1. Twelve- to thirteen-month-old mice injected with ethanol $(4.0 \mathrm{~g} / \mathrm{kg})$ "slept" approximately twice as long as their 2-3-month-old counterparts. When subjected to statistical analysis, this difference was statistically significant $(t=4.36$, $\mathrm{p}<.001)$. However, BAC levels at the time of 


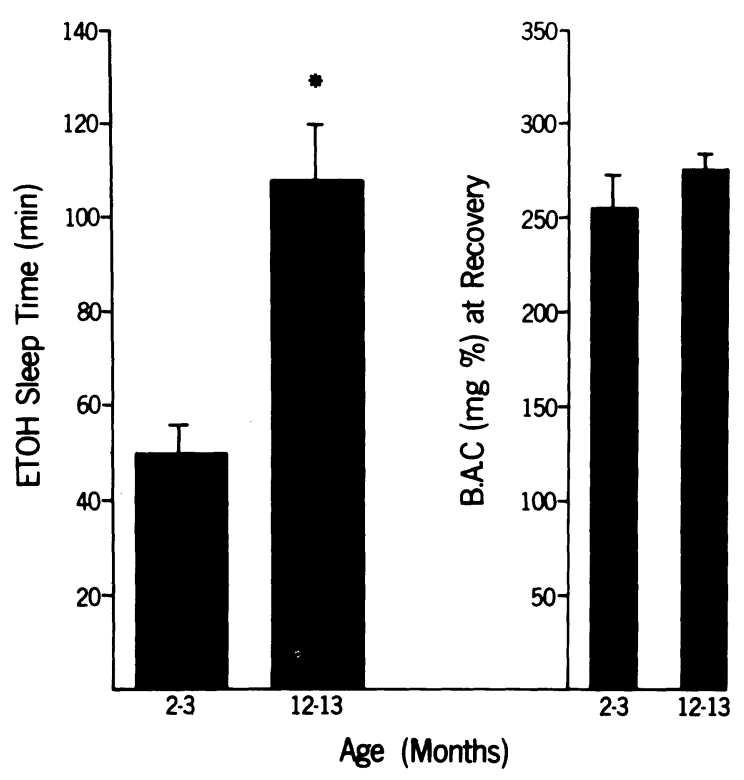

Figure 1. Differential effects of ethanol on "sleep time" in mice of different ages and blood alcohol concentrations (BAC) at time of awakening. Bars represent S.E.M. ${ }^{*} p<.05$.

awakening were not very different $[\mathrm{t}(14)=0.93$, n.s.].

Older mice likewise slept approximately twice as long as their younger counterparts in response to pentobarbital $[\mathrm{t}(18)=5.48, \mathrm{p}<.05]$.

The effects of alcohol on photocell activity are shown in Figure 2. Although older animals were less active than younger animals following injection of alcohol, the differences in activity achieved statistical significance only at a dose of $3 \mathrm{~g} / \mathrm{kg}[\mathrm{t}(22)=2.38$, $\mathrm{p}<.05]$.

Preference data for ethanol are presented in Figure 3. At all concentrations with the exception of $5 \%$ and $10 \% \mathrm{v} / \mathrm{v}$, older animals consumed less ethanol than did their younger counterparts. Preferences for ethanol fell below that for water at a concentration of $25 \% \mathrm{v} / \mathrm{v}$ for older animals. Younger animals ceased their preferences for ethanol at a concentraton of $35 \% \mathrm{v} / \mathrm{v}$.

\section{DISCUSSION}

Older animals are far more susceptible to the toxic effects of ethanol than are younger animals (Wiberg et al., 1970). There is also evidence that although alcohol dehydrogenase (ADH) activity is higher in older animals (Wiberg et al., 1971), the rate of metabolism of alcohol in relatively slower (Wiberg et al., 1970). However, comparable agerelated differences in rate of ethanol metabolism have not been found in man (Kurzinger, 1963; Vestal, McGuire, Tobin, Andres, Norris, \& Mezey,
1977). In the present study, ethanol- and pentobarbital-induced "sleep time" were significantly longer in older mice, although BACs on awakening were not markedly different. This observation is in keeping with Wiberg et al.'s (1970) data of a slower metabolic rate for ethanol in older animals. Observations by Samorajski, Strong, and Sun (1977) indicate that older animals also metabolize barbiturate drugs such as hexobarbital more slowly than younger animals. Since ethanol and barbiturates are metabolized by different enzyme systems (alcohol dehydrogenase and microsomal mixed function oxidase, respectively), it would appear that aging results in an overall inhibition of hepatic enzyme activity.

The effects of ethanol on photocell activity corroborate Samorajski et al.'s (1977) observations using wheel-running activity, and suggest an overall greater sensitivity to the behavioral effects of ethanol as a consequence of aging.

The relationship between aging and ethanol preference showing greater ethanol preference by

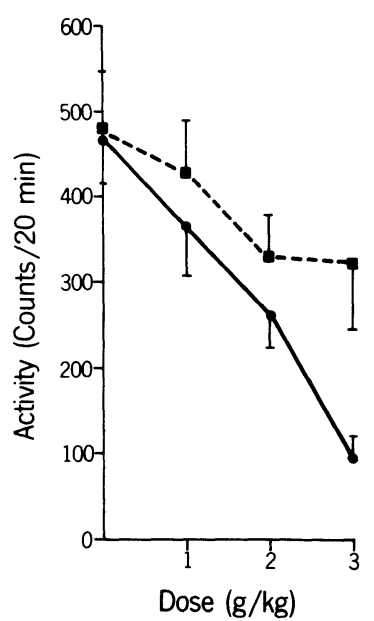

Figure 2. Effects of ethanol on photocell activity in 2-3-monthold (---) and 12-13-month-old (-) mice. Points represent means, bars represent S.E.M.

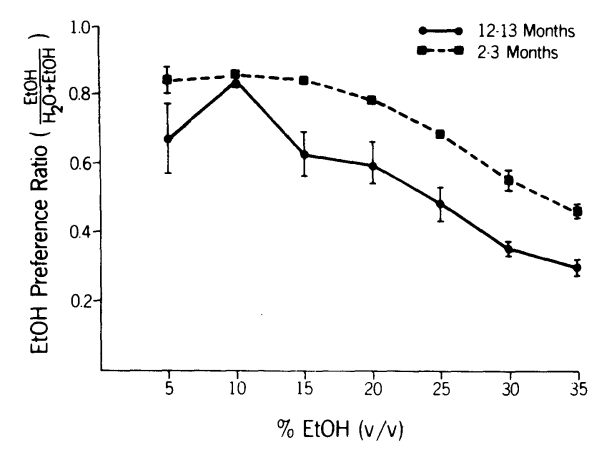

Figure 3. Differential effects of age on preference for ethanol in mice. Points represent means, bars represent S.E.M. 
younger animals corroborates previous studies in mice and rats, using a more limited range of concentrations of ethanol (Goodrick, 1967, 1975; Sprott \& Symons, Note 1). Genotypic differences in preference for ethanol are well known (McClearn, Bennett, Herbert, Kakihanna, \& Schlensinger, 1964; McClearn \& Rodgers, 1959, 1961). These differences have been shown to be positively correlated with ADH levels (McClearn et al., 1964; McClearn \& Rodgers, 1959, 1961), and ADH has been found to be several times higher in older than in younger animals (Wiberg et al., 1971). However, while preference has been shown to be positively correlated with ADH levels, it has not been found to be significantly correlated with actual in vivo metabolic rates (Rodgers, McClearn, Bennett, \& Herbert, 1963). This latter finding would suggest that age-related differences in ethanol preferences are not due to differences in metabolic rate.

Alternatively, age-related differences in ethanol preference may be due to differences in taste sensitivity. However, experimental evidence indicates that sensitivity declines with age in animals and man (e.g., Glanville, Kaplan, \& Fischer, 1964; Goodrick, 1967; Richter \& Campbell, 1940). If taste were a factor in the present study, one would expect that, with reduced taste sensitivity, older animals would exhibit a greater preference for ethanol than younger animals, but just the opposite occurred. It is possible, however, that, with very old animals (e.g., 24 months), a greater preference for ethanol may be observed at higher concentrations (Goodrick, 1967).

The present data demonstrating age-related differences in response to ethanol do not permit any conclusions regarding the underlying factors responsible for these differences. However, the fact that aging affects the response to ethanol has important implications for geriatric pharmacology, in general and institutional programs in particular, in which alcohol is used to promote social facilitation among the elderly (e.g., Burrill, McCourt, \& Cutter, 1974; Mishara \& Kastenbaum, 1974).

\section{REFERENCE NOTE}

1. Sprott, R. L., \& Symons, J. P. Alcohol preference in young and old mice. Unpublished manuscript, 1975.

\section{REFERENCES}

Barnes, G. M., \& Russell, M. Drinking patterns among adults in Western New York: A descriptive analysis of the sociodemographic correlates of drinking. Buffalo: Research Institute on Alcoholism, 1977.

Burrill, R. H., McCourt, J. F., \& Cutter, H. S. G. Beer: A social facilitator for PMI patients? Gerontologist, 1974, 14, 430-431.
Cahalan, D., \& Cisin, I. H. American drinking practices: Summary of findings from a national probability sample. I. Extent of drinking by population subgroups. Quarterly Journal of Studies on Alcohol, 1968, 29, 130-151.

Epstein, L. J., \& Simon, A. Antisocial behavior of the elderly. California Mental Health Research Digest, 1970, 8, 78-79.

Glanville, E., Kaplan, A., \& Fischer, R. Age, sex and taste sensitivity. Journal of Gerontology, 1964, 19, 474-478.

GoodRICK, C. L. Behavioral characteristics of young and senescent inbred female mice of the $\mathrm{C}_{57} \mathrm{BL} / 6 \mathrm{~J}$ strain. Journal of Gerontology, 1967, 22, 459-464.

GooDRICK, C. L. Behavioral differences in young and aged mice. Strain differences for activity measures, operant learning, sensory discrimination, and alcohol preference. Experimental Aging Research, 1975, 1, 191-207.

Greizerstein, H. B., \& Smith, C. M. Development and loss of tolerance to ethanol in goldfish. Journal of Pharmacology and Experimental Therapeutics, 1973, 187, 391-399.

Kurzinger, R. Das Alkoholabbau bei alten Menschen. Deutche Gesundheit, 1963, 18, 1224-1230.

McClearn, G. E., Bennett, E. L., Herbert, M., Kakihana, R., \& SChlesinger, K. Alcohol dehydrogenase activity and previous ethanol consumption in mice. Nature, 1964, 203, 793-794.

McClearn, G. E., \& Rodgers, D. A. Differences in alcohol preference among inbred strains of mice. Quarterly Journal of Studies in Alcohol, 1959, 20, 691-695.

McClearn, G. E., \& Rodgers, D. A. Genetic factors in alcohol preference in laboratory mice. Journal of Comparative and Physiological Psychology, 1961, 54, 116-119.

MishaRA, B. L., \& KastenbaUM, R. Wine in the treatment of long term geriatric patients in mental institutions. Journal of the American Geriatric Society, 1974, 22, 88-94.

Richter, C., \& Campbell, K. Sucrose taste thresholds of rats and humans. American Journal of Physiology, 1940, 128, 291-297.

Rodgers, D. A., McClearn, G. E., Bennett, E. L., \& Herbert, M. Alcohol preference as a function of its caloric utility in mice. Journal of Comparative and Physiological Psychology, 1963, 56, 666-672.

Samorajski, T., Strong, J. R., \& Sun, A. Y. Dehydroergotoxine (hydergine) and alcohol-induced variations in young and old mice. Journal of Gerontology, 1977, 32, 145-152.

Schuckitt, M. A., \& Miller, P. L. Alcoholism in elderly men: A survey of a general medical ward. Annals of the New York Academy of Sciences, 1976, 273, 558-571.

Sun, A. Y., \& SamorajsKI, T. The effects of age and alcohol on $\left(\mathrm{Na}^{+}+\mathrm{K}^{+}\right)$-ATPhase activity of whole homogenate and synaptosomes prepared from mouse and human brain. Journal of Neurochemistry, 1975, 24, 161-164.

Vestal, R. E., McGuire, E. A., Tobin, J. D., Andres, R., Norris, A. H., \& Mezey, E. Aging and ethanol metabolism. Clinical Pharmacology and Therapeutics, 1977, 21, 343-354.

Wiberg, G. S., Samson, J. M., Maxwell, W. B., Caldwell, B. B., \& Trenholm, H. L. Further studies on the acute toxicity of ethanol in young and old rats: Relative importance of pulmonary excretion and total body water. Toxicology and Applied Pharmacology, 1971, 20, 22-29.

Wiberg, G. S.. Trenholm, H. L., \& Caldwell, B. B. Increased ethanol toxicity in old rats: Changes in $\mathrm{LD}_{50}$ in vivo and in vitro metabolism, and liver alcohol dehydrogenase activity. Toxicology and Applied Pharmacology, 1970, 16, 718-727.

Zimberg, S. The elderly alcoholic. Gerontologist, 1974, 14, 221-224.

(Received for publication March 21. 1978: revision accepted June 6. 1978.) 